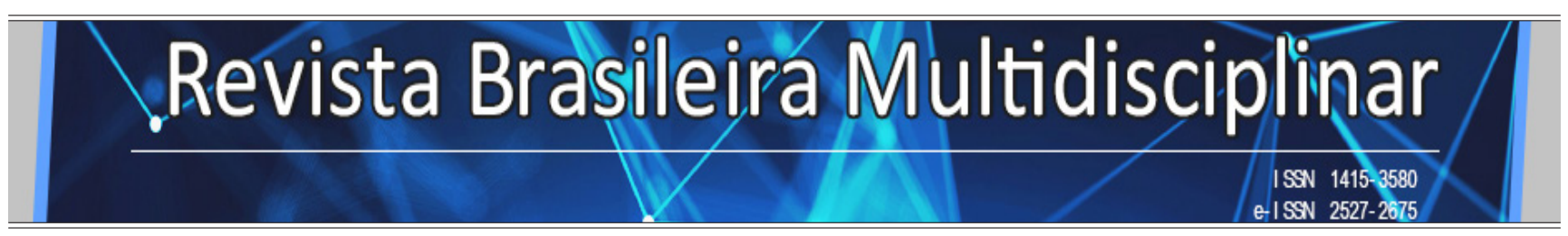

http://revistarebram.com/index.php/revistauniara

\title{
LobBy, NeOINTITUCIONALismo E O PROCESSO DECISÓRIO BRASILEIRO
}

\author{
Monyele Camargo Graciano*; Leandro de Lima Santos*; Luiz Manoel de Moraes Camargo Almeida*** \\ ${ }^{*}$ Doutoranda em Ciência Política pela Universidade Federal de São Carlos. \\ **Doutorado em Sociologia pela Universidade Federal de Goiás, Brasil. \\ ${ }_{*}^{*}$ Doutorado em Sociologia pela Universidade Estadual Paulista Júlio de Mesquita Filho, Brasil. \\ *Autor para correspondência e-mail: arzccb@gmail.com
}

\section{Palavras-chave}

\section{Sistema político}

Instituições informais

Lobby

\section{KEYWORDS}

Political system

Informal Institutions

Lobby

\section{RESUMO}

O presente artigo tem como escopo contribuir com a discussão a respeito das instituições informais no contexto brasileiro e também investigar o lobby como um modelo desse tipo de instituição no processo de tomada de decisão política, a partir da tipologia de Helmke e Levitsky. As instituições informais são concebidas como regras socialmente compartilhadas, não divulgadas por meios oficiais e são criadas e disseminadas marginalmente dos instrumentos formais, nesse sentido, a hipótese deste trabalho é que o lobby, concebido como uma atividade organizada voltada para a defesa de interesses específicos pode ser considerado um modelo de instituição informal. Para verificar tal hipótese, a metodologia empregada nesta pesquisa contou como uma abordagem qualitativa valendose de uma revisão bibliográfica acerca da temática proposta. Percebeu-se ao concluir a pesquisa, que o lobby é uma instituição informal, que dentre da tipologia proposta se enquadra como uma "instituição informal acomodada".

\section{Abstract \\ LOBBY, NEOINTITUTIONALISM AND THE BRAZILIAN DECISION-MAKING PROCESS}

This article aims to contribute to the discussion about informal institutions in the Brazilian context and also to investigate the lobby as a model of this type of institution in the process of political decision making, based on the typology of Helmke and Levitsky. Informal institutions are conceived as socially shared rules, not divulged by official means and are created and disseminated marginally from the formal instruments, in this sense, the hypothesis of this work is that the lobby, conceived as an organized activity focused on the defense of specific interests, can be considered a model of informal institution. To verify this hypothesis, the methodology used in this research counted as a qualitative approach using a bibliographical review about the proposed theme. It was realized, at the conclusion of the research, that the lobby is an informal institution, which in the proposed typology is classified as a "well-off informal institution". 


\section{INTRODUÇão}

Nas últimas décadas, um tema relevante para as pesquisa em Ciência Política é a investigação das instituições, em especial, seus efeitos no processo decisório. Muitas pesquisas, focadas sobretudo em instituições disponibilizadas por canais oficiais não conseguiram explicar com plenitude o comportamento político. Nesse sentido, trabalhos voltados apenas para as características formais, como estudos sobre a Constituição Federal, por exemplo, não conseguem representar com clareza e exatidão o comportamento político e tampouco prever seus resultados (O’DONNEL, 1996; HELMKE; LEVITSKY, 2006).

Desse modo, as instituições informais permeiam os sistemas políticos influenciando as instituições formais, principalmente, os sistemas eleitorais, as legislaturas, as decisões judiciais e também outras instituições. Em muitos casos, as regras informais corroboram os sistemas políticos democráticos, já em outros casos, subvertem as instituições formais (HELMKE; LEVITSKY, 2006).

Na experiência brasileira, a Constituição Federal de 1988, legitima o processo político democrático adotado no país, a partir dela, diversas outras instituições formais se criam e se consolidaram, fortalecendo a democracia no Brasil. Nesse sentido, um sistema político é considerado como um instrumento pelo qual as instituições políticas se consolidam, logo, os fatores políticos e institucionais participam do processo de tomada de decisão, fomentando oportunidades para a ação de líderes políticos, bem como para atuação de grupos de interesse (IMMERGUT, 1996).

Para Immergut (1996), o poder dos grupos de interesse está diretamente vinculado aos mecanismos institucionais, uma vez que a relação desses grupos com o sistema político deve ser avaliada por meio da elasticidade das instituições às pressões políticas, propiciando diferentes oportunidades de alavancar ou obstruir uma legislação ou norma, as instituições ponderam o peso dos atores em estratégias mais favoráveis a interesses convergentes ou divergentes. Nesse sentido, os grupos de interesse, buscam a satisfação de suas demandas em detrimento das ofertadas por outros grupos sociais, e é por meio do lobby, que acontece essa advocacia.

O lobby consiste na defesa de interesses junto aos membros do poder público, tendo como escopo influenciar e conquistar benefícios nas decisões políticas referentes às diferentes políticas públicas.

A prática do lobby no Brasil não é regulamentada, diferente de outros países, desse modo, sua participação se dá por vias informais, partindo desse pressuposto este trabalho se vale das seguintes indagações: o lobby pode ser considerado um modelo de instituição informal? Se sim, dentre, as tipologias defendias por Helmke e Levitsky (2006) qual a sua categoria?

Diante desses questionamentos, tem-se como objetivo neste trabalho investigar a partir do conceito, do modus operandi e da tipologia defendida por Helmke e Levitsky (2006) se o lobby pode ser considerado ou não uma instituição informal atuante no sistema político brasileiro, sendo esta a hipótese desta formulação. Ao serem encontrados indicativos que corroborem tal afirmativa, verifica-se a partir de suas peculiaridades em qual categoria o lobby se enquadra na tipologia dos autores já citados.

Para tanto, o contorno metodológico deste trabalho valeu-se de uma abordagem qualitativa, buscando através de uma revisão bibliográfica sobre Neoinstiutcionalismo, instituições formais e informais, lobby e os estudos desenvolvidos por Helmke e Levitsky (2006) acerca da temática, contribuir com o debate a respeito da relevância das instituições para a democracia e o sistema político brasileiro.

O trabalho encontra-se disposto em quatro seções, a primeira versa sobre a o Neoinstitucionalismo, a segunda trata sobre as instituições informais e a sua tipologia, a terceira aborda as instituições informais no arranjo político brasileiro e por último, a quarta traz a discussão do lobby como modelo de instituição informal no Brasil.

\section{O NEOINSTITUCIONALISMO}


Nas décadas de 1960 e 1970 houve uma disseminação nas análises de Ciência Política, do enfoque orientado pelo comportamento individual, ele norteava-se pelos arranjos informais de poder e não pela instituições formais. Esse modelo acarreta uma mudança do foco teórico das estruturas e das regras para os comportamentos dos indivíduos, perdurando por alguns anos nas pesquisas, excluindo as instituições de grande parte das pesquisas realizadas no período. (HALL; TAYLOR, 2003).

Contudo, as instituições voltam aos debates políticos nas décadas de 1980 e 1990, no que se convencionou chamar de Neoinstitucionalismo, na perspectiva de March e Olsen (2008), essa nova corrente correspondia a uma abordagem epistemológica relevante para as Ciências Sociais, podendo ser concebida a partir de um conjunto de ideias que buscavam reduzir a dependência do Estado organizado com a sociedade, em proveito de relação interdependente entre as instituições sociais e políticas autônomas.

Segundo Hall e Taylor (2003) o Neoinstitucionalismo não é uma corrente unificada na Ciência Política, e possui três métodos de análise diferentes que apareceram a partir de 1980 , eles os denominaram como: Institucionalismo Histórico, Institucionalismo da Escolha Racional e Institucionalismo Sociológico, ainda que tenham concepções distintas essas correntes visam investigar o papel desempenhado pelas instituições e sua relação com determinantes sociais e políticos.

A primeira vertente, é intitulada por Institucionalismo Histórico, tem como principal argumento que a instituições são dotadas de laços políticos, sociais e históricos que a influenciaram. (THELEN; STEINMO, 1992). Os defensores dessa corrente, segundo Hall e Taylor (2003), acreditam que há uma causalidade originada pela trajetória social percorrida, path dependent, assim, os institucionalistas históricos, possuem o foco no papel que as instituições desempenham na vida política, porém, para eles existem outros fatores, como, o cultural e o históricos, que motivam a vida política. Em suas palavras, Hall e Taylor (2003), afirmam que:

De modo geral, procuram situar as instituições numa cadeia causal que deixe espaço para outros fatores, em particular os desenvolvimentos socioeconômicos e a difusão das idéias. Desse ponto de vista, apresentam um mundo mais complexo que o universo de preferências e de instituições com freqüência postulado pelos teóricos da escola da escolha racional. (HALL; TAYLOR, 2003, p.201).

A segunda corrente, é o Institucionalismo Sociológico, que, conforme ensina segundo Hall e Taylor (2003), possui uma ótica específica, o defensores dessa corrente sustentaram que muitos dos procedimentos institucionais adotados pelas organizações nem sempre são os mais eficazes, muitas vezes isso ocorre a partir da difusão dessas práticas, consideradas para os adeptos como práticas culturais. Em suas palavras, Hall e Taylor (2003), defendem que:

(...) os institucionalistas sociológicos sustentam que as organizações adotam com freqüência uma nova prática institucional por razões que têm menos a ver com o aumento da sua eficiência do que com reforço que oferece à sua legimitidade social a à de seus adeptos. Em outros termos, as organizações adotam formas e práticas institucionais particulares porque elas têm um valor largamente reconhecido num ambiente cultural mais amplo. (HALL; TAYLOR, 2003, p.211).

O Institucionalismo da Escolha Racional é a terceira tendência do Neoinstitucionalismo, originado a partir da Economia, essa abordagem, segundo North (1990) defende que as instituições são definidas como as "regras do jogo", que ajustam o comportamento dos indivíduos ao cenário político ou social. Nesse sentido, os sujeitos agem racionalmente buscando estratégicas para maximizarem seus interesses dentro do desenho institucional. Nessa perspectiva, Hall e Taylor (2003), afirmam que: 
os teóricos da escola da escolha racional tendem a considerar a vida política como uma série de dilemas de ação coletiva, definidos como situações em que os indivíduos que agem de modo a maximizar a satisfação dos suas próprias preferências o fazem com o risco de produzir um resultado sub-ótimo para a coletividade (HALL; TAYLOR, 2003, p.205).

Para Blondel (2009) o conceito de instituição não pode ser aplicado da mesma maneira a todas as ciências sociais, dessa forma como as três versões do neoinstitucionalismo tiveram suas origens a partir da Economia, da Ciência Política e da Sociologia, seus fundamentos e características irão depender da sua gênese, entrementes, as três abordagens têm sido aplicadas às pesquisas da Ciência Política, especialmente, no campo das políticas públicas.

\section{AS INSTITUIÇÕES INFORMAIS E A SUA TIPOLOGIA}

As instituições sociais e políticas moldam o comportamento das pessoas e definem seus interesses partir da sua relação com os demais indivíduos e com grupos de poder. As regras institucionais determinam os incentivos e/ou os constrangimentos. Logo, as instituições estabelecem meios estratégicos para conduzir ação dessas pessoas, modificando o conflito político (STEINMO et al.,1992).

Diante disso, as instituições podem ser definidas como regras, normas, procedimentos, dentre outras, que buscam padronizar as comportamentos através da imposição de constrangimentos ou incentivos aos sujeitos. (NORTH, 1990; BLONDEL, 2009). Em suas palavras, Blondel (2009), explica que:

No contexto da Ciência Política, a busca por uma definição tem que ser em torno do conceito de organizações capazes de tomar decisões autoritativas, estes órgãos sendo capazes de desenvolver práticas, isto é, procedimentos e regras, que aqueles que as reconhecem têm que aceitar como sendo, por assim dizer, as "armas e pernas" dessas organizações. (BLONDEL, 2009, p.8).

Nesse sentido, Hall e Taylor (1996) enfatizam que o modo pelo qual as instituições influenciam o comportamento das pessoas, muitas vezes não afetam somente o cálculo estratégico dos indivíduos, conforme defendido pela corrente da escolha racional, induz as suas preferências. Logo, as instituições, causam efeitos nas relações humanas, condicionando ações estratégicas dos sujeitos e das organizações.

A depender da forma como as instituições são criadas, elas podem ser de natureza formal ou informal, segundo North (1990), esse dois modelos coexistem e podem se relacionar, a compreensão dessa dualidade se dá a partir da atuação e dos interesses dos sujeitos envolvidos por essas instituições, sendo possível considerar os dois conjuntos.

As instituições formais podem ser consideradas como aquelas que derivam de um sistema legal, consolidado a partir de normas expressas que conta com o conhecimento e a anuência dos sujeitos, ainda que, coersivamente. Por sua vez, as instituições informais são regras, socialmente compartilhadas, que foram criadas e disseminadas fora dos canais oficialmente permitidos. Muitas vezes, as instituições informais estão presentes no seio de instituições formais (HELMKE; LEVITSKY, 2006).

Nas democracias, existem instituições que, a depender forma de como são observadas pelos pesquisadores, não são reconhecidas como um elemento relevante para o desenho político, essas instituições, segundo O’Donnel (1996) são as informais, que possuem um conjunto de interações não normatizadas, mas que são reconhecidas, aceitas e praticadas pelos indivíduos em acordo com as regras por elas determinadas.

Assim, as regras informais influenciam nos sistemas eleitorais, nas legislaturas, nas decisões judiciais e em outras instituições formais democráticas. Em muitos casos, as regras informais, reforçam os sistemas políticos democráticos, por sua vez, em outros casos, as enfraquecem, fomentando meios para subvertê-las. 
Outra característica importante sobre as instituições informais é que elas também moldam os resultados institucionais das instituições formais, ainda que de modo mais modesto, porém igualmente importante. (HELMKE; LEVITSKY, 2006).

Nesse sentido, Helmke e Levitsky (2006) criaram um tipologia para as instituições informais, que se baseia em duas dimensões, a primeira diz respeito ao grau da convergência ou divergência entre os resultados institucionais formais e informais, segundo os autores, as regras informais produzem resultados semelhantes às regras formais, assim diz que eles se convergem, ao mesmo passo, quando ocorre um resultado diferente do formal pode-se dizer que as instituições informais apresentam também divergência.

A segunda dimensão é a eficácia das instituições formais, entendida, por Helmke e Levitsky (2006) como o momento que as normas e procedimentos são aplicados e/ou cumpridos na prática, ou seja, o ponto no qual as instituições formais são eficazes, assim, quando ocorre o descumprimento destas, os sujeitos acreditam que existirão sanções, no mesmo sentido, quando regras e os procedimentos formais são ineficazes a possibilidade de punição é baixa.

A partir dessas duas dimensões, tem-se a tipologia da instituições informais, que podem assumir quatro categorias distintas: as complementares, as acomodadas, as concorrentes e as substitutivas. As instituições informais complementares, para Helmke e Levitsky (2006) moldam o comportamento dos indivíduos sem que ocorra a violação das regras formais, assim, em seus resultados haverá eficácia e eles terão convergência com as regras formais. Em muitos casos esse modelo de instituição informal é utilizado para melhorar os níveis de eficiência e/ou eficácia das instituições formais.

As instituições informais complementares são divididas em dois subgrupos: as que são destinadas para o preenchimento de lacunas dentro das instituições formais e as que são bases para a consolidação das instituições formais, pois, muitas vezes, o cumprimento das regras formais são conquistados a partir de experiências preexistentes compartilhadas ou criadas através das normas informais. (HELMKE; LEVITSKY, 2006).

O segundo modelo das instituições informais são as acomodadas, que criam incentivos para que os sujeitos se comportem de determinadas maneiras alterando os efeitos das regras formais sem necessariamente violá-las, ou seja, elas subvertem o espírito, mas não modificam a forma das regras formais. Esse modelo de instituição informal muitas vezes é criado pelos atores que buscam resultados diferentes dos gerados por meio das regras formais. (HELMKE; LEVITSKY, 2006).

As instituições informais concorrentes, formam o terceiro grupo, esse modelo coexiste com as instituições formais ineficazes e geram resultados divergentes. As instituições informais estruturam incentivos de modo incompatível com as regras formais, logo, para seguir uma regra formal, os atores devem violar a informal e vice-versa. De modo geral, as instituições informais concorrentes superam as instituições formais, fomentando resultados que divergem acentuadamente. (HELMKE; LEVITSKY, 2006).

O último grupo de instituições informais é composto pelas instituições informais substitutivas, essa categoria combina instituições formais ineficazes e resultados compatíveis, assim como nas instituições complementares, esse modelo busca resultados semelhantes com as regras e com os procedimentos formais. Assim, esse tipo de instituição informal consegue alcançar o que as instituições formais foram designadas a cumprir e no entanto falharam em seu caminho, com efeito, as instituições substitutivas geralmente emergem em estruturas estatais fracas ou ineficazes. (HELMKE; LEVITSKY, 2006).

A seguir, no Quadro 1, encontra-se disposto um esquema que auxilia na compreensão das quatro categorias de instituições informais e as suas duas dimensões. 
Quadro 1 - Tipologia das Instituições Informais

\begin{tabular}{|c|c|c}
\hline $\begin{array}{l}\text { Resultados/ } \\
\text { Eficácia }\end{array}$ & $\begin{array}{c}\text { Formal eficaz } \\
\text { Instituições }\end{array}$ & $\begin{array}{c}\text { Formal ineficaz } \\
\text { Instituições }\end{array}$ \\
\hline Convergente & Complementar & Substituto \\
\hline Divergente & Acomodando & Competindo \\
\hline
\end{tabular}

Fonte: HELMKE; LEVITSKY, 2006

Essa tipologia, desenvolvida por Helmke e Levitsky colabora na melhor compreensão da relação entre instituições formais e informais, desse modo, a partir desse modelo é possível observar que há laços mais complexos entre elas, e que, muitas vezes são desconhecidos em virtude de uma abordagem unitária.

Portanto, segundo Helmke e Levitskyas (2006) as instituições informais podem gerar efeitos perniciosos sobre um sistema democrático e influir na qualidade das instituições democráticas podendo também ampliar os graus de governabilidade, e consequemente, contribuir para a estabilidade das instituições formais, na existência de um Estado fraco e ineficiente.

\section{AS INSTITUIÇões INFORMAIS NO ARRANJO POLÍTICO BRASILEIRO}

No processo político decisório, as instituições balizam o comportamento dos agentes políticos, pois, a partir delas, são criadas as respectivas estratégias de ação. (IMMERGUT, 1996). Assim, torna-se relevante compreender também as regras de caráter informal e verificar como essas instituições informais interagem entre si na busca do melhor resultado. Logo, compreender a dinâmica das regras informais, permite perceber a complexidade do processo legislativo. (VILPOUX; OLIVEIRA, 2010)

Muitas pesquisas desenvolvidas no Brasil sobre o processo decisório firmam-se somente por meio das instituições formais, desprezando, a influência de regras ou procedimentos informais atinentes ao processo legislativo, segundo, Desposato (2006), isso ocorre, porque se atentam apenas às regras expressas, como o regimento interno das casas legislativas ou a Constituição Federal.

Após o período de redemocratização e a criação de normas trazidas pelo texto constitucional, foi concebido um conjunto de regras sobre a divisão dos poderes institucionais concernentes ao Executivo e ao Legislativo, tal arranjo deu sustentação ao processo decisório e consequentemente, estabeleceu os parâmetros para o funcionamento do sistema político brasileiro. (LIMONGI; FIGUEIREDO; VALENTE, 2000).

Assim, as normas constitucionais disciplinam as relação do Poder Executivo e o Poder Legislativo, o federalismo, os sistemas eleitorais, os partidos políticos dentre outros, essas características são concebidas como elementos determinantes para a consolidação dos sistemas democráticos. Contudo, nos países latino-americanas, o desempenho das democracias tem evidenciado que o comportamento dos agentes políticos não são estabelecidos, em muitos casos são previstos somente a partir das instituições formais. (HELMKE; LEVITSKY, 2006).

$\mathrm{Na}$ especificidade brasileira, é possível investigar o processo decisório na transposição dos efeitos ocasionados à partir do arranjo institucional e os diversos agentes envolvidos. Segundo Santos (2003), a 
peculiaridade das instituições brasileiras em combinação com sistema presidencialista, a representação proporcional e a fragmentação do sistema partidário, a bicameralidade e modelo federativo de república conduz à uma dinâmica política sem precedentes no mundo que, de forma muito específica, baliza todo a engenharia institucional do país.

No processo legislativo, vários elementos e sujeitos distintos interagem de modo complexo, pois a votação por uma aprovação ou rejeição de uma proposição legislativa demanda um percurso de tomada de decisão cercado pela influência das instituições formais informais. (FERREIRA JÚNIOR, et al.,2012).

Nesse sentido, Immergut (1996, p.144), defende que "um sistema político é a maneira pela qual as instituições políticas repartem os votos entre diferentes jurisdições, em combinação com a distribuição partidária desses votos." Portanto, fatores políticos e institucionais desencadeiam lógicas complexas para a tomada de decisão, criando oportunidades e limites diversos para a ação de líderes políticos, bem como de grupos de interesses. Para Truman (1998) o grupo de interesse é uma agremiação que tem por base um ou vários comportamentos de participação, que busca a defesa de determinadas reivindicações em detrimento das ofertadas por outros agrupamentos sociais. No contexto político, um grupo de interesse é formado por sujeitos que, para além das mesmas pretensões, promovem pleitos através do arranjo institucional, buscando influenciar o processo de tomada de decisão. Esses grupos são instituições que se valem das regras informais para alcançar suas pretensões junto ao Congresso Nacional e a Câmara dos Deputados.

Grupo de interesses é todo grupo de pessoas físicas e/ou jurídicas, formal ou informalmente ligadas por determinados propósitos, interesses, aspirações ou direitos (...). Grupo de pressão é o grupo de interesse dotado de meios humanos e materiais necessários e suficientes - e da 18 vontade de utilizá-los ativamente, para a promoção dos seus objetivos, até vê-los atingidos (FARAHT, 2007, p.146).

Segundo Diniz e Boschi (2003), o meio utilizado pelos grupos na defesa de seus interesses é o lobby, que por sua vez se mostra como o processo de atuação de determinados grupos no processo decisório, a influência de um grupo de interesse pode ocorrer antes da consolidação da política pública por exemplo.

\section{O LOBBY COMO MODELO DE INSTITUIÇÃO INFORMAL}

A palavra "lobby" possui origem inglesa e significa, antessala, em sua tradução literal. O pioneiro no estudos sobre lobby na Ciência Política foi Arthur F. Bentley (1908), em sua pesquisas, o autor já utilizava o termo para designar influências no processo de decisão política. (OLIVEIRA, 2005).

Segundo Graziano (1994, apud Oliveira 2005), o lobby teve origem nos Estados Unidos com a política de interesses após as eleições de 1896, como desdobramento derrota do movimento operário, desse modo, o lobby é considerado como um meio para a equiparação política, valendo-se de estratégias e dos meios diversos até então desconhecidos. Nesse sentido, em sua palavras Oliveira afirma:

O lobbying surgiu como processo de diálogo entre grupos de interesses econômicos e o governo, tendo sido apropriado por organizações que não tinham motivos econômicos, as quais poderiam ser denominadas de entidades sociais ou idealísticas, comprovando a validade do processo para representar interesses perante os agentes governamentais. (OLIVEIRA, 2005, p.30).

Nessa perspectiva, para Graziano (1994 apud Oliveira 2005),) o lobby consiste em um instrumento que os grupos de interesses utilizam para participar do processo de tomada de decisões, influenciando na elaboração das políticas públicas. Com efeito, os grupos se valem de uma rede complexa de atividades de que incluem a coleta de informações, propostas políticas, estratégias eficazes para satisfação de suas 
demandas, confecção de pesquisas e a procura por aliados. Diante disso, Ferreira (2015) defende que:

O lobby deve ser entendido como a defesa dos interesses junto dos membros do poder público, com o objetivo de influenciar e obter benefícios nas decisões políticas referentes às diferentes políticas públicas. Deste modo, o lobby centra a sua atuação no momento prévio à tomada das decisões políticas. Isto é, a sua atividade desenvolve-se nas etapas que antecedem a decisão política final, quer ocorra no âmbito do poder executivo, quer no poder legislativo. (FERREIRA, 2015, p.15).

Diante disso, segundo Farhat (2007) um grupo de interesse articula diretamente ou indiretamente com os tomadores de decisão política e requer um posicionamento destes agentes, torna-se, então, um grupo de pressão, ou seja, os grupos de pressão são grupos de interesse que exercem pressão, diante disso, o autor defende que o lobby age pelo convencimento pessoal baseado em informações confiáveis, e também por meio da pressão ofertada por esses grupos.

Portanto, a atividade de lobby pode ser exercida sobre diversos sujeitos, individualmente ou coletivamente, por certo, em sua maioria, advém através de entidades organizadas formalmente ligadas à atividades econômicas ou sociais (como o empresariado rural e ou grupos religiosos) ou com finalidades específicas conduzidas tradicionalmente pelo lobby (federações e sindicatos de empresários e de trabalhadores). Essas organizações visam influir nas decisões políticas, não exercendo propriamente a legitimidade para atuar na tomada de decisão, diferenciado-se dos partidos políticos. (MANCUSO; GOZETTO, 2011).

O Lobismo se fortaleceu no arranjo político brasileiro após o período da redemocratização. Segundo, Diniz e Boschi, (2003), esse fato ocorreu em virtude da acessibilidade ao processo de tomada de decisões política. O principal locus do lobby é o Poder Legislativo, estando presente em todos os entes da federação. A atividade de lobby pode ser relacionada com de anseios ideológicos, religiosos, econômicos entre outros. (GRAZIANO, 1996; MANCUSO; GOZETTO, 2011).

Ainda com fortes raízes no parlamento brasileiro o lobby ainda não é uma atividade regulamentada, agindo por meio de instrumentos institucionais informais. Contudo, apesar da falta de regulamentação, o lobby é praticado sem embargos no Congresso Nacional. (SANTOS; CUNHA, 2015).

O lobby se condiciona perante o âmago da decisão política, buscando influenciar por meio da pressão os agentes políticos no processo de tomada de decisão, beneficiando determinados grupos, sejam eles caráter social ou empresarial. (BORIN ,1988). Nesse sentido, Furlan (2011, p.145) dispõe que "O processo legislativo não escapa da cooptação pelo poder econômico, muitas vezes protagonizada pelos lobbies, que ainda tecem influências sobre políticas públicas e decisões governamentais como um todo".

Segundo Carvalho (2009), outro ponto atinente ao debate sobre o lobby e sua atuação na arena política é a ambiguidade quanto à sua legitimidade, pois quando utilizado pelos grupos sociais, como os sindicatos, percebe-se que sua credibilidade é consolidada, porém, quando é utilizado pelo setor privado, existe uma certa desconfiança quanto sua fidedignidade. Essa ambivalência creditada ao lobby decorre em virtude da sua informalidade, podendo ser usado para caracterizar diversas situações, inclusive de algumas de cunho antidemocrático, como é o caso de ações envolvendo corrupção.

Assim, o lobby, mesmo não possuindo uma regulamentação a partir das instituições formais, encontrase presente no cenário político brasileiro, em especial, no processo decisório de políticas públicas, via esforços para influenciar na tomada de decisão, podendo ser considerada uma instituição informal, sendo assim, dentro da tipologia definida por Helmke e Levitsky (2006) pode ser considerada uma instituição informal acomodada.

Logo, o lobby, como instituição informal acomodada opera em um contexto formado por instituições 
formais eficazes, pois, o sistema político brasileiro, possui uma Constituição Federal rígida, na qual há dispositivos que regulam e consolidam as instituições formais, (como exemplos, a divisão dos poderes, $\mathrm{o}$ federalismo, a democracia, a bicameralidade, os partidos políticos, dentre outros), mas que em virtude dos incentivos criados pelos lobistas (informações técnicas, apoio partidário e financiamento de campanha) pode alterar os resultados oriundos dessas instituições formais, sem necessariamente, violá-las.

\section{CONSIDERações Finais}

Neste artigo pretendeu-se investigar sobre o lobby e as instituições no processo político brasileiro. As instituições moldam o comportamento dos indivíduos e condicionam seus interesses. Por sua vez, as regras institucionais fomentam incentivos ou entraves que influenciam as ação dos sujeitos.

As instituições podem se dar de dois tipos as formais e as informais, a primeira consiste no modelo que baseia-se nas normas preescritas ou expressas no ordenamento legal do país, por sua vez, as normas informais, são aquelas socialmente compartilhadas, não escritas, porém replicadas e aceitas pela a sociedade.

Em muitos casos, as regras informais reforçam os sistemas políticos democráticos, intensificando as instituições formais, ou, em outros casos, as enfraquecem, por certo, as regras informais moldam os processos e resultados políticos.

A hipótese que norteou este trabalho considerava que o lobby poderia ser concebido como uma instituição informal inerente ao sistema político do país, ao longo da pesquisa foi possível verificar indicativos que corroboraram tal hipótese, logo, o lobby é compreendido como um meio pelo qual se vale os grupos de interesse para participar do processo de tomada de decisão, influenciando na elaboração de políticas públicas.

No Brasil, o lobby ainda não possui uma regulamentação própria, entretanto, está presente no cenário político, em especial, no processo decisório, buscando influenciar a tomada de decisão política, podendo assim ser concebido como uma instituição informal atuante e com grande poder de barganha no Congresso Nacional.

Diante disso, buscou-se identificar em qual categoria, da tipologia apresentada por Helmke e Levitsky (2006), o lobby se enquadraria, ao analisar suas caraterísticas e relacionar com os quatro grupos de instituições, definidas na tipologia, as quais são, a complementar, a concorrente, a acomodada e a substitutiva, percebeu-se que ele é uma instituição informal acomodada, pois é atuante em um cenário político composto por instituições formais eficazes, como a divisão dos poderes, o federalismo, a democracia, a bicameralidade, os partidos políticos, dentre outros, que no entanto busca criar incentivos para coordenar ou alterar os resultados oriundos dessas instituições formais com o intuito de defender suas demandas, sem precisar violar ou subverter as instituições formais brasileiras.

\section{REFERÊNCIAS}

BLONDEL, J. About Institutions, Mainly, but not exclusively, Political, In: Rhodes, R. A. W., S. A. Binder and B. A. Rockman (Eds.), The Oxford Handbook of Political Institutions. Oxford, Oxford University Press, 2009.

BORIN, J. O Lobby na Imprensa: tipificação e formas de atuação. Cadernos de Jornalismo e Editoração. São Paulo, n. 22, 1988, p. 61-70.

CARVALHO, F. S. O Papel dos Grupos de Interesse e Pressão na Formatação e Fortalecimento da demo- 
cracia brasileira: o Caso do Departamento Intersindical Assessoria Parlamentar(Diap) durante o processo da Constituinte (1987/1988) Brasileira. Aurora (Unesp. Marília), v. 5, p. 32-39, 2009.

DESPOSATO, SCOTT W. How Informal Electoral Institutions Shape the Brazilian Legislative Arena. In: HELMKE, Gretchen; LEVITSKY, Steven. Informal Institutions and Democracy: Lessons from Latin America, Baltimore, The Johns Hopkins University Press, 2006.

DINIZ, E.; BOSCHI, R. Empresariado e estratégias de desenvolvimento. Revista Brasileira de Ciências Sociais, v. 18, n. 52, 2003.

FARHAT, S.. Lobby, o que é, como se faz: ética e transparência na representação junto a governos. São Paulo: Peirópolis, 2007.

FERREIRA JUNIOR, N.A; PERLIN, G.D.B; ROCHA, A.B. Reforma política no parlamento brasileiro: considerações a partir da rejeição política do projeto de lei 1210 de 2007. E-legis, Brasília, n. 9, p. 24-51, 2012. Disponível em: http://e-legis.camara.leg.br/cefor/index.php/e-legis/article/view/108/116 - Acesso 27 jul. 2018.

FERREIRA, R. M. Z. Os grupos de interesse e a sua intervenção nas políticas públicas: regulamentação e supervisão através do estudo do sistema dos Estados Unidos da América. Cadernos de Dereito Actual, v. 3, p. 9-27, 2015.

FIGUEIREDO, A;C; LIMONGI, F.; VALENTE, A; L., "Governabilidade e Concentração de Poder Institucional: O Governo FHC”. Tempo Social, v. 11, n. 2, 200.

FURLAN, F; F. A corrupção como fenômeno político e seu papel na degradação do Estado democrático de Direito. Belo Horizonte: Faculdade de Direito da Pontifícia Universidade Católica de Minas Gerais, 2011.

HALL, P. A.; TAYLOR, R. Political science and the three new institutionalisms. Political Studies, n. 44, p. 936-957, 1996.

Três versões do neoinstitucionalismo. Lua Nova, São Paulo, n. 58, 2003, p. 193-223.

HELMKE, G; LEVITSKY, S. Informal Institutions and Democracy: Lessons from Latin America, Baltimore, The Johns Hopkins University Press, 2006.

IMMERGUT, E. M. As regras do jogo: a lógica da política de saúde na França, na Suíça e na Suécia. Revista Brasileira de Ciências Sociais, v.11, n. 30, p. 139-165, 1996.

LODI, J.B.. Lobby: Os Grupos de Pressão. Editora: Pioneira, 1986, São Paulo

MARCH, James G; OLSEN, Johan P. Neo-institucionalismo: fatores organizacionais na vida política. Rev. Sociol. Polit., Curitiba, v. 16, n. 31, p. 121-142, Nov. 2008.

MANCUSO, W.; GOZETTO, A. C. O.Lobby: uma discussão introdutória sobre oito questõeschave. Rev. 
Eletrônica Portas, v.4, n.4, p.10-21, jun.2011

NORTH, D. C. Institutions, institutional change and economic performance. Nova Iorque. Cambridge University Press, 1990.

O’DONNEL, G. Otra Institucionalización. Política y Gobierno, vol. 3, número 2, 1996.

OLIVEIRA, A. C. de J., Lobby e Representação de Interesses: lobistas e seu impacto sobre a representação de interesses no Brasil. UNICAMP, Campinas, Fev. 2004.

SANTOS, F. O Poder Legislativo no presidencialismo de coalizão. Belo Horizonte: Ed. UFMG; Rio de Janeiro:IUPERJ, 2003.

SANTOS, M. L.; CUNHA, L.. Percepções sobre a regulamentação do lobby no Brasil: convergências e divergências. Brasília: Rio de Janeiro: IPEA, out. 2015.

STEINMO, S.; THELEN, K.; LONGSTRETH, Frank (orgs.) Structuring politics: historical institutionalism in comparative analysis. New York: Cambridge Univ.,1992.

THELEN, K.; STEINMO, S.. Historical institutionalism in comparative politics. In: STEINMO, Sven; THELEN, Kathleen; LONGSTRETH, Frank (orgs.) Structuring politics: historical institutionalism in comparative analysis. New York: Cambridge Univ.,1992.

TRUMAN, D.B. The Governmental Process. New York: Knopf, 1951. p. 544.

VILPOUX, Olivier F.; OLIVEIRA, Eule José de. Instituições informais e governanças em arranjos produtivos locais. Rev. econ. contemp., Rio de Janeiro, v. 14, n. 1, p. 85-111, 2010 . 